\title{
Safe and sustainable: the extracranial approach toward frontoethmoidal meningoencephalocele repair
}

\author{
Paul I. Heidekrueger, MD, ,19 Myat Thu, MBBS, FRCS(Edin), ${ }^{2}$ Wolfgang Mühlbauer, MD, PhD, ${ }^{3}$ \\ Charlotte Holm-Mühlbauer, MD, PhD, ${ }^{3}$ Philippe Schucht, MD, PhD, ${ }^{2,4}$ Hans Anderl, MD, PhD, ${ }^{5}$ \\ Heinrich Schoeneich, MD, ${ }^{6}$ Kyawzwa Aung, MD, ${ }^{7}$ g Mg Ag, MD, ${ }^{2}$ Ag Thu Soe Myint, MD, ${ }^{2}$ \\ Sabrina Juran, PhD, ${ }^{8}$ Thiha Aung, MD, ${ }^{9}$ Denis Ehrl, MD, ${ }^{1}$ Milomir Ninkovic, MD, PhD, ${ }^{1}$ and \\ P. Niclas Broer, MD, PhD'1
}

'Department of Plastic, Reconstructive, Hand, and Burn Surgery, StKM-Klinikum Bogenhausen, Academic Teaching Hospital, Technical University Munich; ${ }^{3}$ Department of Plastic and Aesthetic Surgery, ATOS Clinic; ${ }^{6}$ Department of Plastic and Reconstructive Surgery, Interplast Germany, Section Munich; ${ }^{9}$ Center of Plastic, Hand, and Reconstructive Surgery, University Medical Center Regensburg, Germany; ${ }^{2}$ Department of Neurosurgery, Yangon General Hospital, Yangon; ${ }^{7}$ Department of Neurosurgery, Mandalay University Hospital, Mandalay, Myanmar; ' ${ }^{4}$ Department of Neurosurgery, University Hospital Inselspital and University of Bern, Switzerland; ${ }^{5}$ Department of Plastic and Reconstructive Surgery, Innsbruck University Hospital, Innsbruck, Austria; and ${ }^{8}$ Population and Development Branch, Technical Division, United Nations Population Fund, New York, New York

\begin{abstract}
OBJECTIVE Although rare, frontoethmoidal meningoencephaloceles continue to pose a challenge to neurosurgeons and plastic reconstructive surgeons. Especially when faced with limited infrastructure and resources, establishing reliable and safe surgical techniques is of paramount importance. The authors present a case series in order to evaluate a previously proposed concise approach for meningoencephalocele repair, with a focus on sustainability of internationally driven surgical efforts.
\end{abstract}

METHODS Between 2001 and 2016, a total of 246 patients with frontoethmoidal meningoencephaloceles were treated using a 1-stage extracranial approach by a single surgeon in the Department of Neurosurgery of the Yangon General Hospital in Yangon, Myanmar, initially assisted by European surgeons. Outcomes and complications were evaluated.

RESULTS A total of 246 patients (138 male and 108 female) were treated. Their ages ranged from 75 days to 32 years (median 8 years). The duration of follow-up ranged between 4 weeks and 16 years (median 4 months). Eighteen patients (7.3\%) showed signs of increased intracranial pressure postoperatively, and early CSF rhinorrhea was observed in 27 patients $(11 \%)$, with $5(2 \%)$ of them requiring operative dural repair. In 8 patients, a decompressive lumbar puncture was performed. There were 8 postoperative deaths (3.3\%) due to meningitis. In 15 patients $(6.1 \%)$, recurrent herniation of brain tissue was observed; this herniation led to blindness in 1 case. The remaining patients all showed good to very good aesthetic and functional results.

CONCLUSIONS A minimally invasive, purely extracranial approach to frontoethmoidal meningoencephalocele repair may serve well, especially in middle- and low-income countries. This case series points out how the frequently critiqued lack of sustainability in the field of humanitarian surgical missions, as well as the often-cited missing aftercare and dependence on foreign supporters, can be circumvented by meticulous training of local surgeons.

https://thejns.org/doi/abs/10.3171/2017.5.PEDS1762

KEY WORDS frontoethmoidal meningoencephalocele; neural tube defects; humanitarian mission; sustainability; NGO; surgical mission; meningocele; craniofacial

$\mathrm{P}$ ERFORMING complex neurosurgical and plastic-reconstructive surgical procedures remains a challenging task, especially when faced with suboptimal clinical circumstances, as may be encountered in middle- and low-income countries. One condition requiring a com- prehensive interdisciplinary approach is frontoethmoidal meningoencephalocele. A frontoethmoidal meningoencephalocele is a congenital deformity characterized by an externalization of brain tissue and meninges through a cranial bone defect (cranium bifidum) at the junction of

ABBREVIATIONS CSF = cerebrospinal fluid; NGO = nongovernmental organization.

SUBMITTED February 16, 2017. ACCEPTED May 8, 2017.

INCLUDE WHEN CITING Published online July 21, 2017; DOI: 10.3171/2017.5.PEDS1762. 
the frontal and ethmoidal bones, usually covered by skin. While $75 \%$ of all meningoencephaloceles are located occipitally and $10 \%-12 \%$ parietally, the frontoethmoidal defect occurs in $13 \%-15 \%$ of cases. ${ }^{1,6}$ Along with anencephaly and spina bifida, this malformation is one of the 3 most common neural tube defects. While its etiology and pathogenesis are still not fully understood, genetic and environmental factors, including maternal malnutrition during pregnancy and teratogenic agents, have been discussed as contributing factors. ${ }^{30,36,39,41}$ Frontoethmoidal meningoencephaloceles can be classified as nasofrontal, nasoethmoidal, nasoorbital, and combined types, depending on the intra- to extracranial extent of the herniated tissues. While the frontoethmoidal form is extremely rare in the Western world (incidence 1 in 35,000), it affects children in poor rural areas of lower income countries more often ${ }^{34,37}$ and is relatively common in Southeast Asia, with an incidence ranging from 1 in 3500 to 1 in 6000 live births. ${ }^{25}$ There is a wide spectrum of clinical manifestations, ranging from symptom free to occurrence of hydrocephalus, spastic palsies, seizures, or intellectual disability. The malformation is associated with craniofacial disfigurement, functional impairment, and risk of infection of the central nervous system. Affected patients may also suffer from telecanthus, ${ }^{3,28}$ amblyopia, and epiphora. ${ }^{8}$ The typical history of the disease is progressive, with continuous herniation of intracranial contents, decreasing life expectancy drastically. Prognosis and treatment of affected patients depend on the location, size, and contents of the herniation, ${ }^{13}$ but in case of progressive externalization of tissue, a definitive surgical repair should be performed in infancy? A combined intra- and extracranial approach, performed within the 1st year of life in a multidisciplinary setting, remains the gold standard for such correction. $., 14,15,19,29$

A complete extirpation of the herniated tissue is necessary to prevent further infections and deformities, or even episodes of meningitis with cerebral involvement. Unfortunately, such highly complex intracranial procedures cannot be performed safely everywhere in the world, and especially not in low-income countries with impaired health care systems and a lack of appropriate service facilities and medical personnel.

In 2008, Holm et al. ${ }^{16}$ described a series of 52 Burmese patients with frontoethmoidal meningoencephaloceles that were operated on by means of a purely extracranial approach. The surgeries were performed between 2001 and 2005 in cooperation with the local Department of Neurosurgery of Yangon General Hospital in Myanmar, and were made possible by personnel and financial support from Interplast Germany, an international nongovernmental organization (NGO) without political or religious affiliations. The chief of the Yangon General Hospital's Department of Neurosurgery (M.T.) was trained in the new technique during a visit to Austria (see Illustrative Case 1, below) and during 3 visits to Myanmar by the Interplast team, which included 5 of the authors (H.A., W.M., C.H.M., H.S., and P.H.) as well as German and Austrian support staff. The new technique avoids the usually necessary additional cranial opening to access the anterior fossa. Despite the difficulties regarding long-term follow-up, the authors concluded that this surgical ap- proach was associated with low early postoperative complications and morbidity rates, while being simple, safe, and cheap. ${ }^{16}$ Since 2005 , the project has been continued with only marginal financial support from Interplast. In 2012, Swiss Neurosurgeons International joined forces to boost the educational program needed to treat the population of over 50 million people living in Myanmar. Thanks to yearly educational visits to Myanmar and numerous fellowships in Switzerland for young Burmese specialists to deepen their skills and knowledge, the number of surgeons able to treat frontoethmoidal meningoencephaloceles has increased exponentially, and nationwide coverage will be reached before the end of this decade.

The goal of the present study was to evaluate whether the proposed treatment approach was in fact adopted by the local medical community, and whether it continued to prove to be a safe procedure with good outcomes in the long run. This is one of the largest series evaluating patients with frontoethmoidal meningoencephaloceles corrected by a purely extracranial approach. Furthermore, this project displays an example of how to overcome the often-discussed potential lack of sustainability in the field of medical humanitarian work, allowing the successful treatment of otherwise often-neglected patients.

\section{Methods}

Between 2001 and 2016, a total of 246 patients with frontoethmoidal meningoencephaloceles were treated using a 1-stage extracranial approach by a single surgeon in the Department of Neurosurgery of the Yangon General Hospital in Yangon, Myanmar. To allow demonstration of surgical management, 1 patient, accompanied by the senior local surgeon, was taken to Austria to undergo surgery. In the past 20 years, the Munich section of Interplast Germany has been performing 3-5 surgical missions per year in Myanmar and has developed a well-organized and widespread medical infrastructural network in the country. With the help of local trustees, affected patients were screened and registered in the different regions and brought to the former capitol city of Yangon for surgery. After the patients underwent preoperative clinical and radiographic examination (skull radiographs and CT scans), their lesions were classified using the frontoethmoidal encephalomeningocele classification according to Rojvachiranonda et al. ${ }^{32}$

As previously described in detail, ${ }^{16}$ the procedure itself entails an extracranial approach through a vertical midline nasal incision, dissection of the meningocele up to the neck of the sac, amputation of the sac and herniated brain up to the level of the inner table of the skull, repair of the dura, bone defect closure with split-thickness calvarial bone or cartilage graft, nasal bone reconstruction, and medial canthoplasty. Local rearrangement flaps were used as needed to achieve closure.

All patients received prophylactic perioperative antibiotic treatment (ampicillin) and were kept in the hospital for 1 week after surgery. Patients were told to stay near the hospital for another 2-4 weeks before returning to their homes, which are frequently in rural areas of Myanmar. If postoperative cerebrospinal fluid (CSF) leakage occurred, bed rest was ordered and prolonged intravenous antibiotic 
treatment was administered. In cases of clinical signs of elevated brain pressure, a decompressive lumbar puncture was performed. If spontaneous cessation of liquorrhea did not occur within 2 weeks after surgery, dural repair was performed by the local neurosurgical team.

Early postoperative complications and outcomes were analyzed, and the aesthetic results were evaluated by taking into consideration anatomical features, including a long-nose deformity, telecanthus, and the position of the medial canthi.

\section{Results}

A total of 246 patients with a median age of 8 years (range 75 days to 32 years) were treated using the described approach. Nasofrontal meningoencephalocele was diagnosed in 105 cases (42.7\%), nasoethmoidal in 65 $(26.4 \%)$, nasoorbital in 5 (2\%), and combined nasoethmoidal/nasoorbital meningoencephalocele in 71 (28.9\%); 71 meningoceles (combined nasoethmoidal/nasoorbital) were bilateral. Bone defect closures with tabula externa grafts were necessary in 64 cases $(26 \%)$. The duration of postoperative follow-up ranged from 4 weeks to 16 years (median 4 months).

Eighteen patients (7.3\%) showed signs of increased intracranial pressure postoperatively, which was the indication for performing the placement of a ventriculoperitoneal shunt. Early CSF rhinorrhea was observed in 27 patients (11\%) postoperatively, but only $5(2 \%)$ of them required operative dural repair. In the other 22 patients, liquorrhea resolved spontaneously under conservative therapy. In 8 patients, a decompressive lumbar puncture was performed. There were 8 postoperative deaths due to meningitis (mortality rate $3.3 \%)$. In 15 patients $(6.1 \%)$, recurrent herniation of brain tissue was observed, and this unfortunately led to blindness in 1 case. Patient demographics and postoperative outcomes are summarized in Tables 1 and 2.

\section{Illustrative Cases \\ Case 1}

This 4-year old boy presented to the neurosurgical clinic in Yangon suffering from a large frontonasal meningoencephalocele (Fig. 1A). An interdisciplinary treatment plan was established and the patient was flown to the University Hospital Innsbruck, Austria, in the company of the senior local Myanmar surgeon so that he could participate in the operation and observe the surgical procedure and perioperative care under optimal conditions (Fig. 1BF). Follow-up 3 and 16 years postoperatively showed an acceptable aesthetic result and full functionality (3-year follow-up photograph, Fig. 1G). The patient is fully integrated into society and creates artwork for family income (Fig. 1H).

\section{Case 2}

This 5-year-old boy presented to the clinic in Yangon with a bilateral nasoethmoidal meningoencephalocele. The surgical approach included exposure of the sac and resection of the herniated tissue. After dural repair, the defect was covered with parietal tabula externa bone grafts and closed with double advancement skin flaps. At 16
TABLE 1. Patient demographic and clinical characteristics in 246 cases of meningoencephalocele treated using an extracranial approach

\begin{tabular}{lc}
\hline \multicolumn{1}{c}{ Characteristic } & Value \\
\hline Sex & \\
\hline Male & 138 \\
\hline Female & 108 \\
\hline Age & 8 yrs \\
\hline Median & 75 days-32 yrs \\
\hline Range & $65(26.4)$ \\
\hline Classification & $105(42.7)$ \\
\hline Nasoethmoidal & $5(2.0)$ \\
\hline Nasofrontal & $71(28.9)$ \\
\hline Nasoorbital & $64(26.0)$ \\
\hline Combined nasoethmoidal/nasoorbital & \\
\hline $\begin{array}{l}\text { Bone defect closure w/ split-thickness calvarial } \\
\text { bone graft }\end{array}$ & 4 mos \\
\hline Follow-up & 3 wks-15 yrs \\
\hline Median & \\
\hline Range & \\
\hline Values presented as the number of patients (\%) unless otherwise indicated.
\end{tabular}

years' follow-up, the patient is socially integrated with his family, participating in traditional ox-cart racing, and has good functional and aesthetic results (Fig. 2).

\section{Discussion}

Several surgical procedures have been described to treat frontoethmoidal meningoencephaloceles, mostly based on the classic technique as described by Tessier, which includes a combined extra- and intracranial approach by means of a bicoronal incision, craniotomy, meningoencephalocele resection, creation of nasofrontal bone flaps, and facial reconstruction. ., $^{7,11,21-23}$

Surgery, performed in a neurosurgical center as soon as possible to avoid progression of the deformity, is the gold standard for treatment in most Western countries.,11 Given the high complexity of the surgery as well as the nascent state of the health care systems and lack of advanced medical infrastructure, expedited treatment of the disease might unfortunately not always be feasible in many Asian countries, such as Burma, ${ }^{11,16}$ Thailand, ,3,10,26,38,39 Cambodia, $, 112,33,42$ Malaysia, ${ }^{1}$ Indonesia, ${ }^{17,35}$ and Papua New Guinea. ${ }^{18}$ However, it has been shown that treating affected

TABLE 2. Postoperative complications after extracranial repair of frontoethmoidal meningoceles (2001-2016)

\begin{tabular}{lc}
\hline \multicolumn{1}{c}{ Complication } & No. of Patients (\%) \\
\hline CSF leak & $27(11)$ \\
\hline Meningitis & $8(3.3)$ \\
\hline Ventriculoperitoneal shunt & $18(7.3)$ \\
\hline Recurrence & $15(6.1)$ \\
\hline Mortality & $8(3.3)$ \\
\hline
\end{tabular}



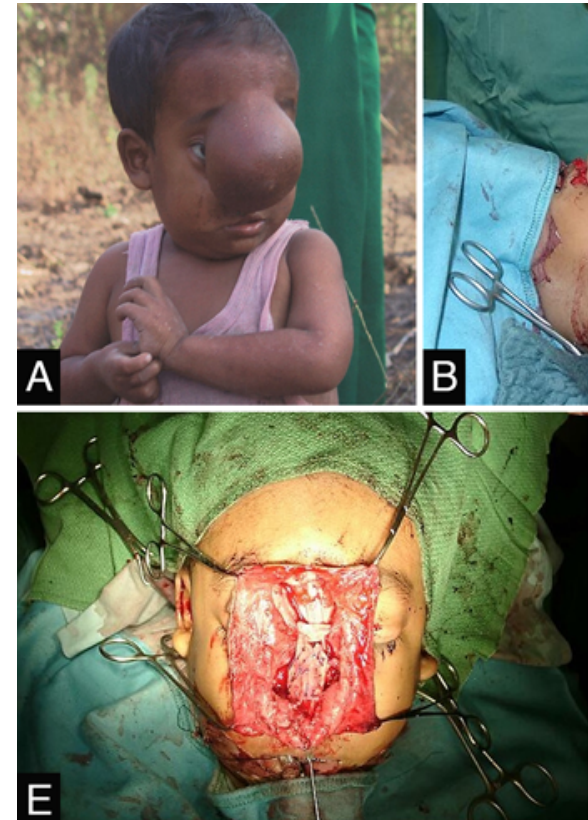
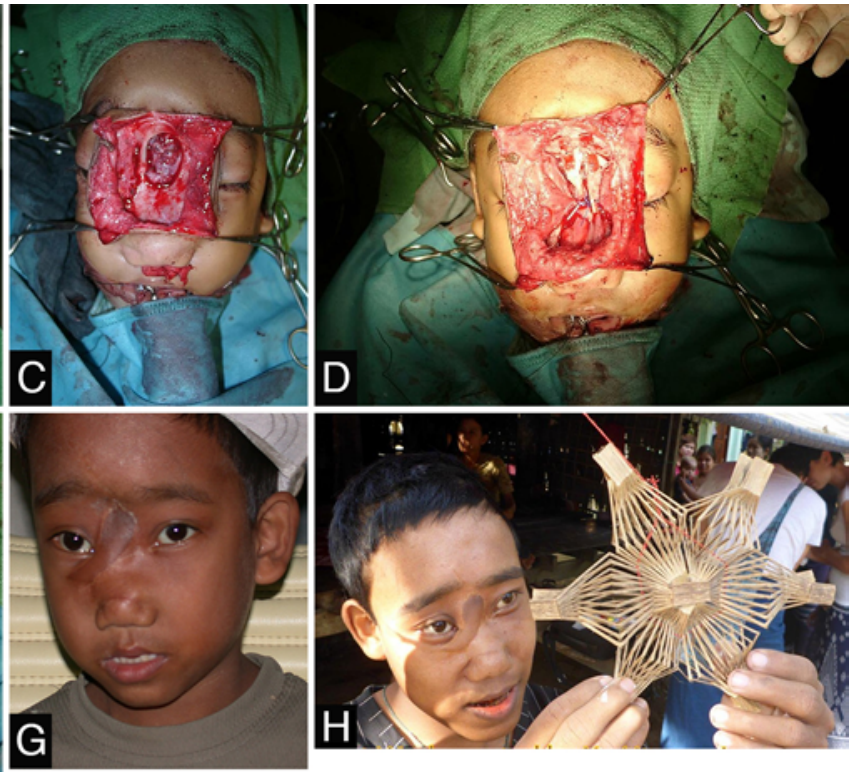

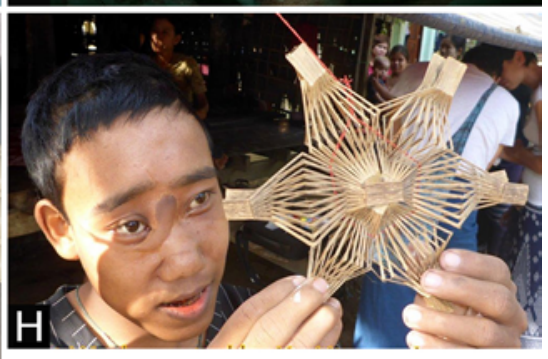

FIG. 1. Illustrative Case 1. A: Preoperative photograph of the patient at the age of 4 years showing a large frontonasal meningoencephalocele. B-F: Intraoperative photographs. The herniated tissue was exposed through a vertical midline incision (B). After resection of the herniated tissue the bone defect was visible $(\mathrm{C})$. The defect was closed with bone grafts after correction of medial hypertelorism by osteotomy and medialization of the medial orbital walls (D). The patient's nose was reconstructed with bone and cartilage grafts (E). Skin closure was achieved with local double-advancement transposition flaps (F). G: Photograph obtained at 3-year follow-up showing the patient with improved aesthetics and a good functional result, including full vision in both eyes. $\mathrm{H}$ : Photograph obtained 16 years after surgery showing the patient with an example of the artwork that he creates to provide for income for his family. Figure is available in color online only.

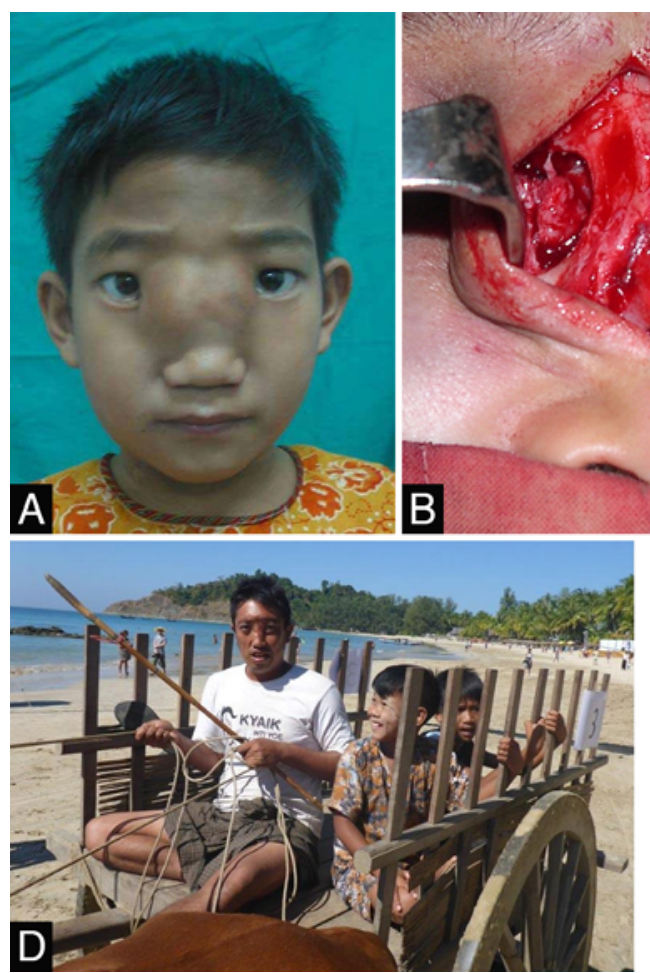

FIG. 2. Illustrative Case 2. A: Preoperative photograph of the patient at the age of 5 years showing a bilateral nasoethmoidal menigoencephalocele. B: Intraoperative photograph showing the bone defect after resection of the herniated tissue through a nasal incision. The defect was subsequently repaired using bone grafts. C: Early postoperative photograph showing an acceptable cosmetic result. D: Photograph obtained 16 years after surgery showing the patient participating in traditional ox-cart racing. Figure is available in color online only. 
TABLE 3. Incidence of postoperative CSF leak associated with different operative techniques

\begin{tabular}{llc}
\hline \multicolumn{1}{c}{ Authors \& Year } & \multicolumn{1}{c}{ Op Technique } & No. of Patients w/ CSF Leak (\%) \\
\hline Mahapatra et al., 1994 & $\begin{array}{c}\text { 2-step procedure in 4 cases; 1-step in 26 cases; combined intra- } \\
\text { \& extracranial approach; no details of technique available }\end{array}$ & $6 / 30(20.0)$ \\
\hline $\begin{array}{l}\text { Fuente del Campo et al., } \\
1989\end{array}$ & $\begin{array}{c}\text { Combined intra- \& extracranial approach; specific approach in } \\
\text { respect to pathology; use of bone graft }\end{array}$ & $2 / 63(3.2)$ \\
\hline Mahatumarat et al., 2003 & Combined intra- \& extracranial approach; "Chula technique" & $3 / 108(2.8)$ \\
\hline Kumar et al., 2009 & Combined intra- \& extracranial approach; "HULA technique" & $0 / 12(0)$ \\
\hline Oucheng et al., 2010 & Combined intra- \& extracranial approach & $24 / 200(12)$ \\
\hline Present study & Purely extracranial approach & $27 / 246(11.0)$ \\
\hline
\end{tabular}

patients under such circumstances can be made possible through the work of joint ventures between local surgeons and NGOs. To do this effectively, highly motivated local surgeons remain an indispensible resource..$^{23,43}$ These need to be provided with continuous development opportunities, including training with visiting professionals as well as rotations at centers of excellence, with international staff and volunteers ultimately only serving in supporting roles. ${ }^{4}$

Regarding frontoethmoidal meningoencephalocele repair, Oucheng et al. ${ }^{27}$ published a series of 200 cases that were treated by a combined neurosurgical-craniofacial approach in Cambodia and showed that good results can be achieved as long as certain surgical and perioperative principles-including clear indications, proper surgical technique, and postoperative care-are adhered to. However, they used a combined intra- and extracranial approach, which is more complex than a solely extracranial procedure. A few years later, Rifi et al ${ }^{31}$ analyzed a series of 60 cases in Africa and were also able to show the feasibility of a 1-step combined procedure, elucidating the importance of repair at an early age as well as the interdisciplinary approach.

In 2008, Holm et al. ${ }^{16}$ introduced the purely extracranial approach for the correction of frontoethmoidal meningoencephaloceles and demonstrated the feasibility and safety of performing the surgery in middle- and low-income countries. While they initially encountered a relatively high incidence of postoperative CSF leaks, the technique has evolved, and leakage rates could be reduced to $11 \%$ in the current series, which is comparable to reports by other groups (Table 3). ${ }^{11,20,24,25,27,31}$ This improvement might be explained by the learning curve as well as the improved availability of adequate instrumentarium and medication in Myanmar. In most patients with a postoperative CSF leak, the leakage ceased spontaneously within 2 weeks after the operation, and craniotomy and secondary dural repair became necessary in only 5 patients ( $2 \%$ of cases). In 8 cases $(3.3 \%)$, ascending meningitis led to postoperative deaths, which might have been due, at least in part, to the suboptimal condition of perioperative hygiene in a developing country hospital. Given the constraints of the medical system, the mortality rate might be difficult to reduce much further; nonetheless, the perioperative management might be improved. Only ampicillin was used for preoperative antibiotic prophylaxis. It was the drug of choice due to its availability, broad-spectrum coverage, and low cost. However, adding sulbactam to extend coverage presents a feasible option for reducing complications. Furthermore, earlier intervention in cases of CSF leaks, which is a widely discussed topic in the literature, will be given consideration in the future. Overall, when comparing the results of this study to reports in the published literature, we found that similar incidences of early postoperative complications were observed by other groups (Table 4), ${ }^{2,3,12,20,21,24,27,28,31}$ In patients with intact craniofacial configuration and only minimal bone defects, this less invasive approach might provide an alternative even in high-income countries; higher-quality prospective studies would be needed to investigate this possibility further, however.

A frequent criticism of case series from low-income countries is poor follow-up. The fact that most patients are

TABLE 4. Early postoperative complications after the correction of frontoethmoidal meningoencephaloceles

\begin{tabular}{lllll}
\hline \multicolumn{1}{c}{ Authors \& Year } & Rhinorrhea & Meningitis & Hydrocephalus & Death \\
\hline Mahapatra et al., 1994 & $6 / 30(20)$ & $1 / 30(3.3)$ & $0 / 30(0)$ & $0 / 30(0)$ \\
\hline Boonvisut et al., 2001 & $3 / 145(2.1)$ & $0 / 145(0)$ & $1 / 145(0.7)$ & $0 / 145(0)$ \\
\hline Pinzer et al., 2006 & $1 / 30(3.3)$ & $0 / 30(0)$ & $0 / 30(0)$ & $1 / 30(3.3)$ \\
\hline Leelanukrom et al., 2007 & $3 / 102(2.9)$ & $1 / 102(1.0)$ & $4 / 102(3.9)$ & $0 / 102(0)$ \\
\hline Gollogly et al., 2008 & $10 / 128(7.8)$ & $3 / 128(2.3)$ & $0 / 128(0)$ & $4 / 128(3.1)$ \\
\hline Kumar et al., 2009 & $0 / 12(0)$ & $0 / 12(0)$ & $0 / 12(0)$ & $0 / 12(0)$ \\
\hline Oucheng et al., 2010 & $24 / 200(12)$ & $6 / 200(3)$ & $4 / 200(8)$ & $3 / 200(6)$ \\
\hline Rifi et al., 2015 & $4 / 60(6.7)$ & $0 / 60(0)$ & $2 / 60(3.3)$ & $1 / 60(1.7)$ \\
\hline Present study & $27 / 246(11)$ & $8 / 246(3.3)$ & $18 / 246(7.3)$ & $8 / 246(3.3)$ \\
\hline
\end{tabular}

Values presented as the number of patients (\%). 
living in remote areas without any established infrastructure makes it very difficult to locate patients and examine them again. In this series also, only a few patients had appropriate follow-up beyond 4-6 weeks. Overall, 15 patients came back to Yangon with recurrent herniation, and they subsequently underwent revision surgery. It is difficult to say whether the purely extracranial approach was associated with an overall higher incidence of recurrence, as has been debated by previous authors. However, the experience of the local surgeons shows that patients who encounter any problems or complications tend to come back to the place where they underwent surgery. One can thus speculate that patients who were doing well during the first 6 weeks after surgery and did not come back continued to do well, but unfortunately there is no guarantee of this, and this uncertainty regarding longer-term outcomes is a major limiting factor of the presented series.

The described approach does show, however, that even complex surgical tasks can be taught to motivated local surgeons who may subsequently continue their efforts and provide safe and efficient care to their people with only minimal additional support.

\section{Conclusions}

Frontoethmoidal meningoencephalocele repair remains a challenging surgical task. A minimally invasive purely extracranial approach may provide a useful option, especially in middle- and low-income countries with inadequate infrastructure and monetary funds. The frequently criticized lack of sustainability in the field of humanitarian surgical missions, as well as the often-cited missing aftercare and dependence on foreign supporters, could be circumvented by meticulous training of local surgeons.

\section{References}

1. Arshad AR, Selvapragasam T: Frontoethmoidal encephalocele: treatment and outcome. J Craniofac Surg 19:175-183, 2008

2. Boonvisut S, Ladpli S, Sujatanond M, Tandhavadhana C, Tisavipat N, Luxsuwong M, et al: Morphologic study of 120 skull base defects in frontoethmoidal encephalomeningoceles. Plast Reconstr Surg 101:1784-1795, 1998

3. Boonvisut S, Ladpli S, Sujatanond M, Tisavipat N, Luxsuwong M, Nunta-aree $S$, et al: A new technique for the repair and reconstruction of frontoethmoidal encephalomeningoceles by medial orbital composite-unit translocation. Br J Plast Surg 54:93-101, 2001

4. Campbell A, Restrepo C, Mackay D, Sherman R, Varma A, Ayala R, et al: Scalable, sustainable cost-effective surgical care: a model for safety and quality in the developing world, part III: impact and sustainability. J Craniofac Surg 25:1685-1689, 2014

5. Chowchuen B, Thanapaisal C, Chowchuen P, Duangthongpon $P$ : Frontoethmoidal meningoencephalocele: challenges and the Tawanchai center's long-term integrated management. J Med Assoc Thai 94 (Suppl 6):S129-S140, 2011

6. Dähnert W: Radiology Review Manual. Philadelphia: Lippincott Williams \& Wilkins, 2007

7. David DJ: Cephaloceles: classification, pathology, and management-a review. J Craniofac Surg 4:192-202, 1993

8. David DJ, Sheffield L, Simpson D, White J: Fronto-ethmoidal meningoencephaloceles: morphology and treatment. Br J Plast Surg 37:271-284, 1984
9. De Vries HR, Maxwell SM, Hendrickse RG: Foetal and neonatal exposure to aflatoxins. Acta Paediatr Scand 78:373378, 1989

10. Flatz G, Sukthomya C: Fronto-ethmoidal encephalomeningoceles in the population of northern Thailand. Humangenetik 11:1-8, 1970

11. Fuente del Campo A, Escanero Salazar A, Baldizon Recio N, Dimopulos A: Transfacial surgical treatment and anthropometric considerations of frontoethmoidal meningoencephaloceles. Ann Plast Surg 23:377-389, 1989

12. Gollogly J, Oucheng N, Lauer G, Pinzer T, Lauwers F, Roux FE, et al: Frontoethmoidal meningoencephalocoele repair in Cambodia: outcomes and cost comparisons. Trop Doct 38:167-170, 2008

13. Gubbels SP, Selden NR, Delashaw JB Jr, McMenomey SO: Spontaneous middle fossa encephalocele and cerebrospinal fluid leakage: diagnosis and management. Otol Neurotol 28:1131-1139, 2007

14. Hilterhaus F, Draf W, Behr R, Bockmühl U: [Management of congenital nasal fistulas and cysts.] Laryngorhinootologie 84:905-909, 2005 (Ger)

15. Hoffmann TK, Scheithauer MO, Sommer F, Lindemann J, Haberl EJ, Friebe-Hoffmann U, et al: Surgery of anterior skull base lesions in children. Ann Otol Rhinol Laryngol 126:245-253, 2017

16. Holm C, Thu M, Hans A, Martina M, Silvia GS, Moritz S, et al: Extracranial correction of frontoethmoidal meningoencephaloceles: feasibility and outcome in 52 consecutive cases. Plast Reconstr Surg 121:386e-395e, 2008

17. Hoving EW, Vermeij-Keers C: Frontoethmoidal encephaloceles, a study of their pathogenesis. Pediatr Neurosurg 27:246-256, 1997

18. Jacob OJ, Rosenfeld JV, Watters DA: The repair of frontal encephaloceles in Papua New Guinea. Aust N Z J Surg 64:856-860, 1994

19. Klein O, Simon E, Coffinet L, Joud A, Ghetemme C, Marchal JC: [Nasal dermal sinus in children: a review based on a series of 6 cases.] Neurochirurgie 60:27-32, 2014 (Fr)

20. Kumar A, Helling E, Guenther D, Crabtree T, Wexler AW, Bradley JP: Correction of frontonasoethmoidal encephalocele: the HULA procedure. Plast Reconstr Surg 123:661669,2009

21. Leelanukrom R, Wacharasint P, Kaewanuchit A: Perioperative management for surgical correction of frontoethmoidal encephalomeningocele in children: a review of 102 cases. Paediatr Anaesth 17:856-862, 2007

22. Macfarlane R, Rutka JT, Armstrong D, Phillips J, Posnick J, Forte V, et al: Encephaloceles of the anterior cranial fossa. Pediatr Neurosurg 23:148-158, 1995

23. Magee WP Jr: Evolution of a sustainable surgical delivery model. J Craniofac Surg 21:1321-1326, 2010

24. Mahapatra AK, Tandon PN, Dhawan IK, Khazanchi RK: Anterior encephaloceles: a report of 30 cases. Childs Nerv Syst 10:501-504, 1994

25. Mahatumarat C, Rojvachiranonda N, Taecholarn C: Frontoethmoidal encephalomeningocele: surgical correction by the Chula technique. Plast Reconstr Surg 111:556-567, 2003

26. Mahatumarat C, Taecholarn C, Charoonsmith T: One-stage extracranial repair and reconstruction for frontoethmoidal encephalomeningocele: a new simple technique. J Craniofac Surg 2:127-134, 1991

27. Oucheng N, Lauwers F, Gollogly J, Draper L, Joly B, Roux FE: Frontoethmoidal meningoencephalocele: appraisal of 200 operated cases. J Neurosurg Pediatr 6:541-549, 2010

28. Pinzer T, Lauer G, Gollogly J, Schackert G: A complex therapy for treatment of frontoethmoidal meningoencephalocele in a developing third world country: neurosurgical aspects. J Neurosurg 104 (5 Suppl):326-331, 2006

29. Re M, Tarchini P, Macrì G, Pasquini E: Endonasal endo- 
scopic approach for intracranial nasal dermoid sinus cysts in children. Int J Pediatr Otorhinolaryngol 76:1217-1222, 2012

30. Richards CG: Frontoethmoidal meningoencephalocele: a common and severe congenital abnormality in South East Asia. Arch Dis Child 67:717-719, 1992

31. Rifi L, Barkat A, El Khamlichi A, Boulaadas M, El Ouahabi A: Neurosurgical management of anterior meningo-encephaloceles about 60 cases. Pan Afr Med J 21:215, 2015

32. Rojvachiranonda N, David DJ, Moore MH, Cole J: Frontoethmoidal encephalomeningocele: new morphological findings and a new classification. J Craniofac Surg 14:847-858, 2003

33. Roux FE, Lauwers F, Oucheng N, Say B, Joly B, Gollogly $\mathrm{J}$ : Treatment of frontoethmoidal meningoencephalocele in Cambodia: a low-cost procedure for developing countries. J Neurosurg 107 (1 Suppl):11-21, 2007

34. Roux FE, Oucheng N, Lauwers-Cances V, Draper L, Cristini C, Collogly J, et al: Seasonal variations in frontoethmoidal meningoencephalocele births in Cambodia. J Neurosurg Pediatr 4:553-556, 2009

35. Sadewa AH, Sutomo R, Istiadjid M, Nishiyama K, Shirakawa T, Matsuo M, et al: C677T mutation in the MTHFR gene was not found in patients with frontoethmoidal encephalocele in East Java, Indonesia. Pediatr Int 46:409-414, 2004

36. Smit CS, Zeeman BJ, Smith RM, de V Cluver PF: Frontoethmoidal meningoencephaloceles: a review of 14 consecutive patients. J Craniofac Surg 4:210-214, 1993

37. Suphapeetiporn K, Mahatumarat C, Rojvachiranonda N, Taecholarn C, Siriwan P, Srivuthana S, et al: Risk factors associated with the occurrence of frontoethmoidal encephalomeningocele. Eur J Paediatr Neurol 12:102-107, 2008

38. Suwanwela C: Geographical distribution of fronto-ethmoidal encephalomeningocele. Br J Prev Soc Med 26:193-198, 1972

39. Suwanwela C, Sukabote C, Suwanwela N: Frontoethmoidal encephalomeningocele. Surgery 69:617-625, 1971

40. Suwanwela C, Suwanwela N: A morphological classification of sincipital encephalomeningoceles. J Neurosurg 36:201211, 1972

41. Thu A, Kyu H: Epidemiology of frontoethmoidal encephalo- meningocoele in Burma. J Epidemiol Community Health 38:89-98, 1984

42. Wangikar PB, Dwivedi P, Sharma AK, Sinha N: Effect in rats of simultaneous prenatal exposure to ochratoxin $\mathrm{A}$ and aflatoxin B1. II. Histopathological features of teratological anomalies induced in fetuses. Birth Defects Res B Dev Reprod Toxicol 71:352-358, 2004

43. Weiser TG, Regenbogen SE, Thompson KD, Haynes AB, Lipsitz SR, Berry WR, et al: An estimation of the global volume of surgery: a modelling strategy based on available data. Lancet 372:139-144, 2008

\section{Disclosures}

The authors report no conflict of interest concerning the materials or methods used in this study or the findings specified in this paper.

\section{Author Contributions}

Conception and design: Heidekrueger, Broer. Acquisition of data: Heidekrueger, Thu, Schucht, K Aung, Mg Ag, Thu Soe Myint, Juran. Analysis and interpretation of data: Heidekrueger, Juran, T Aung. Drafting the article: Heidekrueger, Ehrl. Critically revising the article: Thu, Mühlbauer, Holm-Mühlbauer, Schucht, Anderl. Reviewed submitted version of manuscript: Mühlbauer, HolmMühlbauer, Schucht, Anderl, Schoeneich, K Aung, Mg Ag, Thu Soe Myint, Juran, T Aung, Ehrl, Ninkovic. Approved the final version of the manuscript on behalf of all authors: Heidekrueger. Statistical analysis: Heidekrueger. Administrative/technical/material support: Thu, Mühlbauer, Holm-Mühlbauer, Schucht, Anderl, Schoeneich, K Aung, Mg Ag, Thu Soe Myint, Ninkovic. Study supervision: Broer.

\section{Correspondence}

Paul I. Heidekrueger, Department of Plastic, Reconstructive, Hand, and Burn Surgery, StKM-Klinikum Bogenhausen, Academic Teaching Hospital, Technical University Munich, Englschalkingerstr. 77, Munich 81925, Germany. email: paul@ heidekrueger.net. 